\title{
Psychosis with disulfiram prescribed under probation order
}

\author{
S K Rossiter
}

Disulfiram can cause psychosis and its prescription should not be required under probation orders

Mapperley Hospital, Nottingham NG3 6AA S K Rossiter, staff forensic psychiatrist

BMf 1992;305:763
The courts often require that people who misuse alcohol submit to the care of a named doctor before issuing probation orders. More unusually they may name specific treatments. The case presented here raises questions about the suitability of named drugs being used in court orders.

\section{Case history}

A 32 year old single man presented as an acute emergency case with a clear three day history of paranoid psychosis. He was convinced that there was a conspiracy by "black magicians" to control him and that they were capable of reading his thoughts and of directly controlling his body.

He had presented to psychiatric services in London about 14 months previously when he had been charged with grievous bodily harm. At that time psychiatric reports noted him to have no symptoms or signs of mental disorder but to be an alcoholic of long standing. A probation order was made with a requirement that he take disulfiram in addition to the more usual requirement that he should cooperate with medical supervision by a named doctor. While in the probation hostel he had developed ideas that he was being persecuted by witches and magicians and had once barricaded himself into his room. Being in fear of his life and unable to convince anyone at the hostel that his fears were true, he had absconded from the hostel, stopped taking disulfiram, and started drinking. He subsequently reported feeling much more relaxed while drinking and no longer concerned by his persecutory notions.

He was reapprehended a month later and returned to the hostel where disulfiram was restarted. He seemed anxious, disturbed, and fractious and was transferred to a hostel in the Nottingham area in the hope that being closer to his family, who lived locally, would improve his condition. Shortly after transfer his paranoid symptoms returned and he was admitted to hospital.

Physical examination on admission to hospital showed no signs of withdrawal from alcohol or hepatic dysfunction. His level of consciousness seemed normal and remained so throughout the course of treatment. Serological examination showed no abnormalities of liver function; his vitamin B-12 and folate concentrations were normal.

After admission disulfiram was discontinued and chlorpromazine $100 \mathrm{mg}$ four times daily was started. His paranoid symptoms disappeared completely and he became approachable and unsuspicious. Disulfiram was reintroduced and within 10 days his paranoid delusions recurred; they abated again on stopping disulfiram. No other change in antipsychotic drugs was made during this period. During the two episodes of psychosis observed in hospital there was no evidence of clouding of consciousness or of any disturbances in gait; no headaches or other neurological symptoms or signs were observed.

\section{Discussion}

In 1937 Williams noted that hypersensitivity to ethanol could arise from concurrent use of tetraethylthiuram, which was subsequently introduced into clinical use by Hald et al. ${ }^{2}$ Disulfiram inhibits dopamine $\beta$ hydroxylase, increasing concentrations of dopamine in the mesolimbic system. Given the putative implication of high mesolimbic dopamine concentrations in the pathogenesis of schizophrenia ${ }^{3}$ it is not surprising that some patients taking disulfiram experience psychosis.

Liddon and Satran categorised psychotic reactions into three groups on the basis of 50 observed cases. The first two groups ( 35 patients) had prominent signs of delirium. Only 17 patients had psychoses in clear consciousness. Although delirium usually accompanies psychoses induced by disulfiram, psychosis in clear consciousness has been reported. ${ }^{56}$

Clinicians have been understandably reluctant to restart disulfiram when this is suspected of causing illness, but Quail et al described relapse of paranoid psychosis after rechallenging a patient. In the case reported here psychosis occurred on the three consecutive occasions that disulfiram was given and on the first and third occasions after an appreciable period free from alcohol. This makes it unlikely that either alcohol withdrawal or alcohol masking of underlying psychosis could explain the symptoms described.

This case is also interesting because the crown court made an order for a specific drug to be prescribed as a requirement of probation, rather than the more usual requirement that the patient accede to medical supervision by a named doctor. Discussion with the probation hostel showed that the patient was not medically assessed before restarting disulfiram after his absconscion from the hostel as he had been required to take the drug by the courts.

Transfer to the Nottingham area from a London hostel made it difficult for the named consultant in London to continue supervising him. However, the Nottingham hostel to which he was transferred continued to administer disulfiram without there being any clearly agreed access to medical supervision at that time.

Although the circumstances may be atypical, I suggest that it is inappropriate for courts to require specific drugs to be given when making probation orders as this risks avoidable ill effects.

\footnotetext{
Williams EE. Effects of alcohol on workers with carbon disulfide. FAMA 1937;109:1472-3.

2 Hald J, Jacobson E, Larsen V. The sensitising effect of tetraethylthiuram disulfide (Antabuse) to ethyl alcohol. Acta Pharmacol Toxicol 1948;4:285-96. 3 Nasrallah H. Vulnerability to disulfiram psychosis. West f Med 1979;130: 575-7.

4 Liddon S, Satran R. Disulfiram (Antabuse) psychosis. Am $\mathcal{f}$ Psychiatry 1967;123:1284-9.

5 Ewing J, Mueller R, Rouse P, Siver B. Low levels of dopamine $\beta$-hydroxylase and psychosis. Am f Psyhchiatry 1977; 134:927-8.

6 Knee S, Razani J. Acute organic brain syndrome: a complication of disulfiram therapy. Am F Psychiatry 1974;131:1281-2.

7 Quail M, Karelse R. Disulfiram psychosis. South Afr Med f 1980;57:551.

(Accepted 18 February 1992)
} 